\title{
Differences in breast aesthetic outcomes due to radiation: A validated, quantitative analysis of expander-implant reconstruction
}

\author{
Lauren M Mioton BS¹, Jessica Gaido BS MPH${ }^{2}$, William Small Jr MD², Neil A Fine MD², John Y Kim MD²
}

LM Mioton, J Gaido, W Small Jr, NA Fine, JY Kim.

Differences in breast aesthetic outcomes due to radiation: A validated, quantitative analysis of expander-implant reconstruction. Can J Plast Surg $2013 ; 21(2): 73-77$.

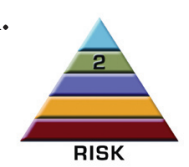

BACKGROUND: The potential ramifications of radiation use can be of particular concern in the breast reconstruction population, in which both surgical and aesthetic outcomes are important. Presently, there remains a paucity of data detailing the influence of radiation on specific reconstruction aesthetic outcomes.

OBJECTIVE: To conduct a quantitative evaluation of aesthetic outcomes for expander-implant breast reconstruction in radiated and nonradiated patients using a validated scoring scale.

METHODS: A series of consecutive expander-implant breast reconstruction operations performed by the senior author between 2004 and 2012 were reviewed. Four blinded members of the Division of Plastic and Reconstructive Surgery at Northwestern University (Illinois, USA) independently rated postoperative photographs of patients' breasts using a validated scoring scale with respect to five distinct aesthetic domains.

RESULTS: Of the 206 patients meeting the inclusion criteria, 69 received radiotherapy and 137 did not. The radiated cohort had lower scores in each aesthetic domain, with significant differences in contour (1.33 versus 1.51; $\mathrm{P}=0.041)$ and placement $(1.45$ versus $1.73 ; \mathrm{P}<0.001)$. Linear regression analysis revealed a significant association between placement scores and radiation, and radiated patients had a significantly higher overall rate of complications.

DISCUSSION: Variances in scores may represent the relative difficulty of expansions and proper implant placement in irradiated tissue, with possible skin fibrosis and decreased flexibility hindering prosthesis manipulation. CONCLUSION: Radiation adversely impacts breast contour and placement, with possible negative contributions to volume, scarring and inframammary fold definition, and results in higher rates of complications. Such detailed evaluation of the impact of radiation on aesthetics will enhance the management of patient expectations.

Key Words: Aesthetic outcomes; Breast reconstruction; Plastic surgery; Radiation; Tissue expander

$\mathbf{R}$ adiation as a treatment modality for breast cancer is often used in Rindividuals undergoing breast conservation therapy and selected patients receiving total mastectomy. Studies have shown that radiation can alter the inherent structure of human tissue and ultimately lead to atrophy or hyperplasia of the epidermis, fibrosis of the dermis, vessel sclerosis and loss of pilosebaceous units (1-8). The potential ramifications of such findings are of particular concern in the subpopulation of patients undergoing breast reconstruction following mastectomy, in which both reconstructive and aesthetic outcomes may be affected $(9,10)$. While numerous studies have analyzed the impact of radiation on expander-implant breast reconstruction outcomes, a thorough literature review by Kronowitz (11) revealed the relative paucity of focused investigations concerning the influence of radiation on

\author{
Les différences d'apparence esthétique des seins en \\ raison des radiations : une analyse quantitative validée \\ d'une reconstruction par expandeur et implant
}

HISTORIQUE : Les ramifications potentielles du recours aux radiations peuvent être particulièrement inquiétantes dans la population de patientes qui subissent une reconstruction mammaire, pour qui les résultats chirurgicaux sont tout aussi importants que les résultats esthétiques. Il existe peu de données détaillant l'influence des radiations sur les résultats esthétiques de la reconstruction.

OBJECTIFS : Au moyen d'un barème de classement validé, procéder à une évaluation quantitative des résultats esthétiques d'une reconstruction mammaire par expandeur et implant chez des patientes ayant ou non subi des radiations.

MÉTHODOLOGIE : Les chercheurs ont analysé une série d'opérations de reconstruction mammaire par expandeur et implant effectuée par l'auteur principal entre 2004 et 2012. Quatre membres en insu de la division de chirurgie plastique et reconstructive de l'université Northwestern, en Illinois, aux Etats-Unis ont classé de manière indépendante les photographies postopératoires des seins des patientes au moyen d'un barème de classement validé dans cinq domaines esthétiques distincts.

RÉSULTATS : Sur les 206 patientes qui respectaient les critères d'inclusion, 69 ont subi une radiothérapie, et 137, non. La cohorte sous radiothérapie présentait un indice plus faible dans le domaine esthétique et des différences significatives sur le plan du contour $(1,33$ par rapport à 1,$51 ; \mathrm{P}=0,041)$ et de l'emplacement $(1,45$ par rapport à 1,$73 ; \mathrm{P}<0,001)$. L'analyse de régression linéaire a révélé une association significative entre le classement de l'emplacement et la radiation, et les patientes ayant subi une radiation présentaient un taux global de complications considérablement plus élevé. EXPOSÉ : La variation des classements peut témoigner de la difficulté relative des expansions et de la bonne mise en place des implants dans les tissus irradiés, l'éventuelle fibrose cutanée et réduction de la flexibilité nuisant à la manipulation de la prothèse.

CONCLUSION : La radiation nuit au contour et à l'emplacement des seins et peut avoir des conséquences négatives sur le volume, la cicatrisation et la définition des plis intramammaires, ce qui peut entraîner un taux plus élevé de complications. Cette évaluation très détaillée des effets des radiations sur l'esthétique permettra de mieux réagir aux attentes des patientes.

aesthetic outcomes. Of the 19 studies evaluated, only one included an assessment of overall cosmesis following expander-implant reconstruction with radiation (12). Consequently, as postoperative complications exacerbated by radiation are discussed, similar statements cannot yet be made regarding radiation and aesthetic outcomes. Other studies have also attempted to quantify overall aesthetics in the setting of radiation, but were limited by small patient populations, nonvalidated scoring scales and/or possible evaluator bias (13-16).

We present the current study as a much needed quantitative evaluation of aesthetic outcomes for expander-implant breast reconstruction in radiated patients. A more defined understanding of how radiation influences aesthetics may be derived from our use of a validated aesthetic scoring scale assessing five important aesthetic domains

${ }^{1}$ Vanderbilt School of Medicine, Nashville, Tennessee; ${ }^{2}$ Division of Plastic and Reconstructive Surgery, Northwestern University, Feinberg School of Medicine; ${ }^{3}$ Department of Radiation Oncology, The Robert H Lurie Comprehensive Cancer Center of Northwestern University, Feinberg

School of Medicine, Chicago, Illinois, USA

Correspondence: Dr John Y Kim, Northwestern University, Feinberg School of Medicine, 675 North St Clair Street, 19-250, Chicago, Illinois 60611, USA. Telephone 312-695-6022, fax 312-695-5672, e-mail jokim@nmh.org 
TABLE 1

Preoperative patient demographics and characteristics

\begin{tabular}{lccc}
\hline & $\begin{array}{c}\text { Nonradiated } \\
(\mathbf{n}=\mathbf{1 3 7})\end{array}$ & $\begin{array}{c}\text { Radiated } \\
(\mathbf{n}=\mathbf{6 9})\end{array}$ & $\mathbf{P}$ \\
\hline Age, years, mean $\pm \mathrm{SD}$ & $51.58 \pm 11.71$ & $47.49 \pm 10.92$ & $0.018^{*}$ \\
$\mathrm{BMI}, \mathrm{kg} / \mathrm{m}^{2}$, mean $\pm \mathrm{SD}$ & $27.32 \pm 6.11$ & $27.72 \pm 5.89$ & 0.666 \\
Diabetes & 2.92 & 2.99 & 1.00 \\
Smoking & 4.38 & 11.59 & 0.052 \\
Hypertension & 22.63 & 15.94 & 0.251 \\
Chemotherapy & 34.31 & 72.46 & $<0.001^{*}$ \\
Antidepressant medication & 54.74 & 42.03 & 0.103 \\
Bilateral & 48.91 & 34.78 & 0.054 \\
\hline
\end{tabular}

Data presented as \% unless otherwise indicated. *Statistically significant (ie, $P<0.05)$. BMI Body mass index

\section{TABLE 2}

\section{Complication profiles of nonradiated and radiated patient} cohorts

\begin{tabular}{lccc}
\hline & $\begin{array}{c}\text { Nonradiated } \\
\text { (n=137) }\end{array}$ & $\begin{array}{c}\text { Radiated } \\
(\mathbf{n}=69)\end{array}$ & $\mathbf{P}$ \\
\hline Overall complications & 13.87 & 26.09 & $0.031^{*}$ \\
Tissue expander explantation $^{\dagger}$ & 10.22 & 13.04 & 0.543 \\
Due to complications & 10.22 & 13.04 & 0.543 \\
Elective & 0.00 & 1.45 & 0.335 \\
\hline
\end{tabular}

Data presented as \% unless otherwise indicated. *Statistically significant (ie, $P<0.05) ;{ }^{\dagger}$ Tissue expander explantation is defined as having removal due to a complication or elective removal. The overall explantation rate may be lower than the individual explantation rates combined

of the breast: breast mound volume; placement; contour; scarring; and inframammary fold definition.

\section{METHODS}

Following institutional review board approval, a retrospective chart review was conducted on a series of consecutive expander-implant breast reconstruction operations performed by the senior author between 2004 and 2012. Demographic, oncological, surgical and photographic data were obtained for each patient. Demographic and oncological variables included age, body mass index (BMI), active smoking status, diagnosed diabetes, postmastectomy $\mathrm{x}$-ray therapy, history of $x$-ray therapy and chemotherapy. Patients included in the present study had postoperative photographic evidence of expanderimplant exchange and a minimum follow-up period of 90 days.

Four blinded members of the Division of Plastic and Reconstructive Surgery at Northwestern University (Illinois, USA), who did not participate in the care of the patients, were asked to independently rate postoperative anterior photographs of patients' breasts using a three-point scale (0 to 2 ) with respect to five distinct aesthetic domains: breast mound volume; contour; placement; scarring; and inframammary fold. Lowery et al (17) described a rating of zero in each of the respective fields as the following: marked difference in volume relative to the contralateral side; marked contour deformity or shape asymmetry; marked displacement of breast mound; hypertrophic scars and evident contracture; and a poorly defined inframammary fold. A score of 1 on the Lowery scale reflected mild discrepancies in volume and contour relative to the contralateral side, fair scarring (ie, poor colour match or wide scars without hypertrophy or contracture) and a defined yet asymmetrical inframammary fold. Any criterion with a score of 2 had quality aesthetic outcomes - specifically, minimal differences in volume, contour and placement, thin scars and symmetrical inframammary folds. Lowery et al (17) also showed this five-domain subscale to have acceptable inter-rater reliability (through kappa score analysis) and superior reliability compared with visual analogue scales.

Aesthetic scores of the radiated and nonradiated cohorts were compared using Student's $t$ tests. Similar analysis was conducted to

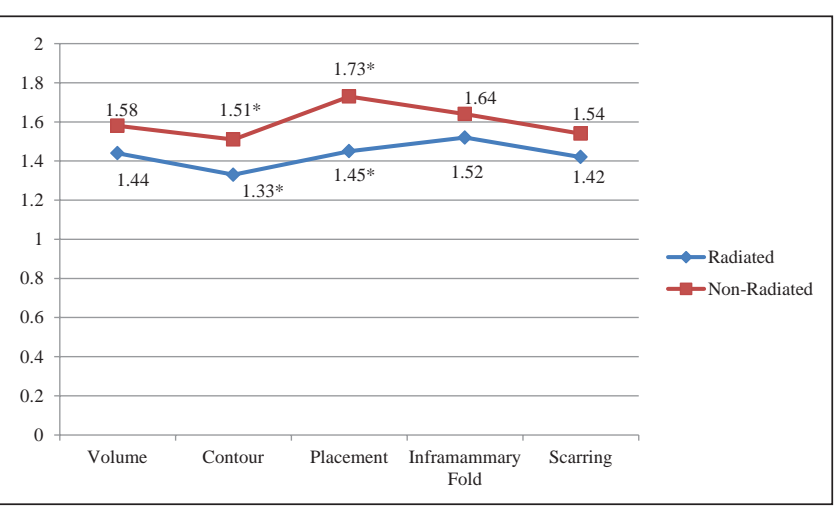

Figure 1) Aesthetic scores in nonradiated and radiated cohorts. *Statistically significant (ie, $P<0.05$ )

compare aesthetic outcomes of pre- and postoperative radiation subgroups within the radiated cohort, as well as aesthetic outcomes of unilateral and bilateral reconstructions in the overall population. Demographic variables were compared using Student's $t$ tests for continuous variables and $\chi^{2}$ or Fisher's exact test for categorical variables, as appropriate. Overall complication was defined as exhibiting one or more of the following: mastectomy flap necrosis or dehiscence; seroma; and infection requiring intravenous antibiotics (ie, National Cancer Institute Common Toxicity Criteria grade 3 or higher). Postoperative outcomes were compared using $\chi^{2}$ or Fisher's exact tests.

Further investigation into the relationship between radiation and aesthetic scores was performed using multivariable linear regression. Acknowledging that baseline differences in patient characteristics between cohorts could impact final aesthetic scores, smoking and chemotherapy use were also included as variables in the regression model. All analyses were performed using SPSS version 20.0 (IBM Corporation, USA).

\section{RESULTS}

Of the 206 patients meeting the inclusion criteria, 69 received radiotherapy and 137 did not undergo radiation. More than one-third of the radiation population had a history of previous radiation $(8.7 \%$ received radiation within 90 days before reconstruction; $26.3 \%$ received radiation $>90$ days before reconstruction); and the remainder received postoperative radiation. The radiated cohort was, on average, younger (47.49 versus 51.58 years; $\mathrm{P}=0.018$ ) and had a significantly higher percentage of patients who received chemotherapy $(72.46 \%$ versus $34.31 \% ; \mathrm{P}<0.001$ ) (Table 1). The two patient populations were relatively similar with respect to other captured characteristics, with no significant differences in BMI, active smoking status, diabetes or hypertension.

Postoperative surgical outcomes are summarized in Table 2. The radiated patient population had a significantly higher rate of overall complications $(26.09 \%$ versus $13.87 \% ; \mathrm{P}=0.031)$. This cohort also trended toward higher rates of tissue expander explantation.

Figure 1 illustrates the aesthetic scoring for each of the five domains (breast mound volume, contour, placement, scarring and the inframammary fold) in radiated and nonradiated patients with reconstruction. Photographic representations of aesthetic outcomes in radiated patients are shown in Figures 2 and 3. The inframammary fold proved to be the highest scoring category in radiated patients, while placement was the highest scoring in the nonradiated group. The lowest scoring category for both cohorts was breast contour. The average scores for contour $(1.51$ versus $1.33 ; \mathrm{P}=0.041)$ and placement $(1.73$ versus $1.45 ; \mathrm{P}<0.001)$ were significantly higher in patients who did not receive radiation compared with those who did. The nonradiated population also trended toward higher aesthetic scores compared with the radiated population for breast mound volume, scarring and inframammary fold definition; however, these did not reach statistical significance. Additional analysis within the radiation cohort revealed 

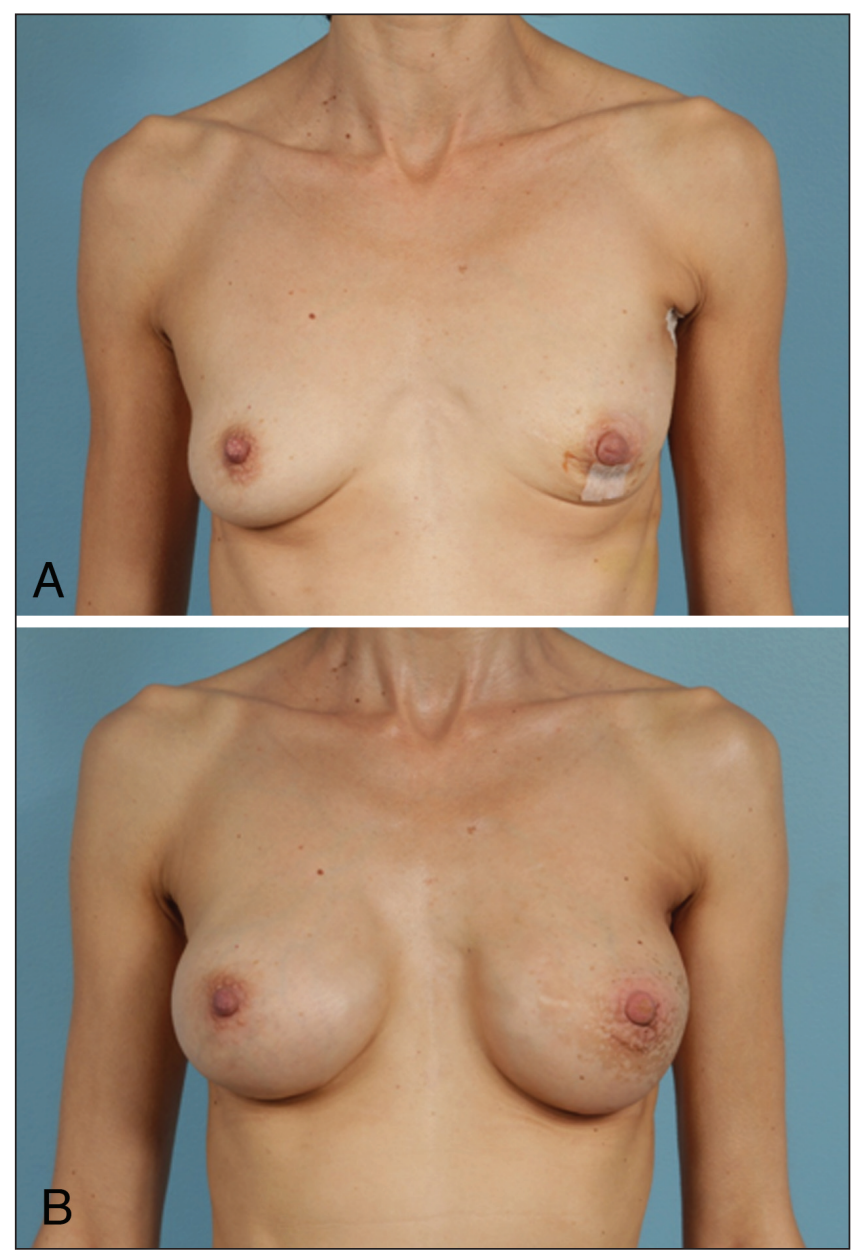

Figure 2) Preoperative (A) and postoperative (B) photographs of aesthetic outcomes in a radiated patient. This 48-year-old woman underwent left nipple-sparing mastectomy with Spectrum (Mentor, USA) implant/expander placement. She underwent postoperative radiation with exchange to silicone implant on the left and right augmentation for symmetry. Figure 2B depicts results 11 months after cessation of radiation therapy

that those who received preoperative radiation had slightly lower, albeit nonsignificant, aesthetic scores compared with those who received postoperative radiation (Table 3 ). With a higher percentage of nonradiated patients undergoing bilateral reconstruction procedures, the impact of laterality on aesthetic outcomes was also examined. The data in Table 4 reveal that bilateral reconstructions had significantly higher aesthetic ratings for breast volume, contour, placement and inframammary fold definition, with a trend toward higher scores for scarring.

Final investigation into the relationship between radiation and aesthetic scores was conducted using linear regression analysis. The results displayed in Table 5 reveal that, after controlling for chemotherapy and smoking, radiation use appeared to have a significant negative association with breast placement.

\section{DISCUSSION}

Radiation - a frequently used adjunct to surgical treatment for breast cancer - may predispose patients to postoperative complications and poorer aesthetic outcomes following reconstruction. An upward trend in mastectomy rates, in concert with the increasing promotion of and participation in breast reconstruction, necessitates a detailed evaluation of how radiation may affect aesthetic outcomes $(1,18)$.

While myriad studies have evaluated the relationship between radiation and postoperative complications, there remains a paucity of data detailing the possible impact of radiation on specific aesthetic
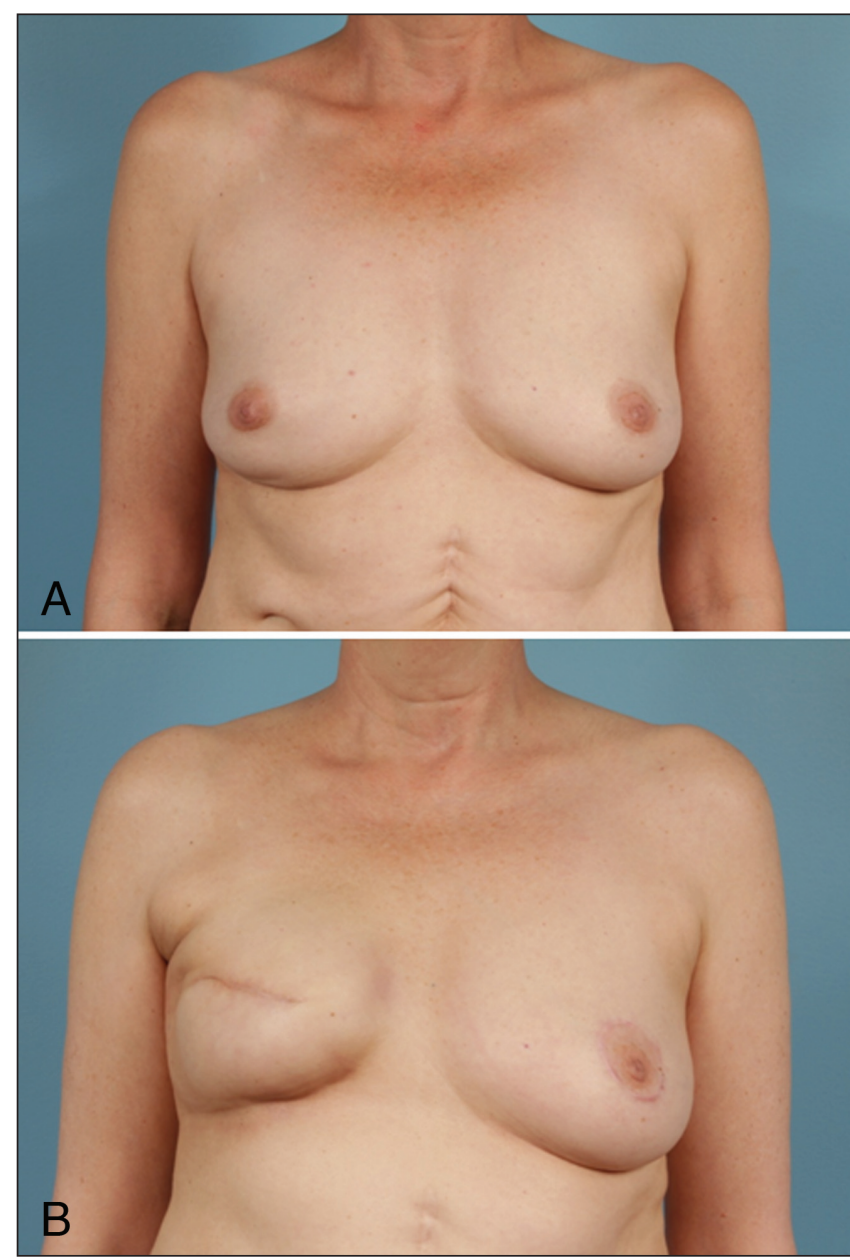

Figure 3) Preoperative (A) and postoperative (B) photographs of aesthetic outcomes in a radiated patient. This 56-year-old woman underwent right skin-sparing mastectomy with expander placement. She subsequently underwent exchange to silicone implant with contralateral mastopexy for symmetry. Note the postoperative tightening and apparent volume loss and elevation of inframammary fold 15 months postradiation therapy

TABLE 3

Aesthetic outcomes in radiated patients stratified according to timing of radiation*

\begin{tabular}{lccc}
\hline Aesthetic domain & $\begin{array}{c}\text { Preoperative } \\
(\mathbf{n}=\mathbf{1 9})\end{array}$ & $\begin{array}{c}\text { Postoperative } \\
(\mathbf{n}=49)\end{array}$ & $\mathbf{P}$ \\
\hline Volume & 1.43 & 1.45 & 0.911 \\
Contour & 1.26 & 1.43 & 0.371 \\
Placement & 1.44 & 1.51 & 0.675 \\
Inframammary fold & 1.49 & 1.58 & 0.483 \\
Scarring & 1.41 & 1.43 & 0.881 \\
\hline
\end{tabular}

*One radiated patient had recorded preoperative and postoperative radiation and was subsequently removed from the analysis

outcomes $(2,3,11,19-44)$. In the small number of studies that have provided information comparing aesthetics in radiated and nonradiated reconstruction patients, most focus on the overall aesthetic appearance of the breast reconstruction and do not provide details regarding specific domains such as breast volume, prosthesis migration and inframammary fold definition (6-9). We present a quantitative comparison of expander-implant breast reconstruction in radiated and nonradiated patients using a validated scoring scale of breast-specific aesthetic domains. 
TABLE 4

The effect of laterality on aesthetics

\begin{tabular}{lccc}
\hline Aesthetic domain & $\begin{array}{c}\text { Unilateral } \\
(\mathbf{n = 1 1 5})\end{array}$ & $\begin{array}{c}\text { Bilateral } \\
(\mathbf{n = 9 1 )}\end{array}$ & $\mathbf{P}$ \\
\hline Volume & 1.32 & 1.81 & $<0.001^{\star}$ \\
Contour & 1.27 & 1.69 & $<0.001^{\star}$ \\
Placement & 1.48 & 1.84 & $<0.001^{\star}$ \\
Inframammary fold & 1.51 & 1.72 & $0.001^{\star}$ \\
Scarring & 1.42 & 1.59 & 0.057 \\
\hline
\end{tabular}

*Statistically significant (ie, $P<0.05$ )

The radiated and nonradiated patient cohorts were comparable in terms of patient demographics and characteristics (Table 1). There was a significantly higher number of patients receiving chemotherapy in the radiated population compared with the nonradiated group $(72.46 \%$ versus $34.31 \% ; \mathrm{P}<0.001)$. In the present study, the use of radiation therapy may have been a reflection of more extensive disease requiring a multifocal approach to therapy that incorporated a combination of chemotherapy, radiation and surgery $(45,46)$. This amalgamation of therapeutic modalities may have also contributed to the elevated overall complication rate witnessed in the radiation cohort because toxicity from these treatments is cumulative. The noted similarities between cohorts reduce the likelihood that patient characteristics significantly impacted outcomes.

On evaluation of aesthetics, the radiated patient population had significantly lower scores for breast contour (1.33 versus 1.51; $\mathrm{P}=0.041)$ and placement $(1.45$ versus $1.73 ; \mathrm{P}<0.001)$ compared with the nonradiated population. Linear regression analysis controlled for chemotherapy use and smoking revealed a sustained negative relationship between radiation and breast placement scores. Procedure laterality could have partially contributed to score discrepancies because our analysis showed bilateral procedures to have significantly higher scores in most domains, and a higher percentage of nonradiated patients underwent bilateral reconstruction. Such variances in scores may also represent the relative difficulty of expansions and proper implant placement in irradiated tissue, with possible skin fibrosis and decreased flexibility hindering prosthesis manipulation. This obstacle may be best reflected by the fact that patients who received radiation before mastectomy had the lowest associated aesthetic scores; these patients likely experienced a greater period of time in which fibrosis of skin and vascular changes could have occurred before reconstruction. Alternatively, adequate expansion and implant placement may have been achieved at the time of exchange, but the continuing structural changes proven to occur in irradiated tissue could have led to contracture of the overlying skin and movement of the affected implant.

There was a trend toward lower scores for radiated patients in the remaining three aesthetic domains - volume, scarring and inframammary fold definition - but these did not reach statistical significance. These findings can be explained, in large part, by the aforementioned changes noted to occur in radiated tissue; fibrosis of surrounding tissue could have affected the final volume of the breast, as well as the potential to create a defined inframammary fold. Poorer scores for scarring may have been due, in part, to slowed healing from the sclerosis of nearby vasculature. While these results are not statistically significant, they may be of clinical significance because studies have shown that aesthetic outcomes are a large contributor to patient satisfaction after reconstruction. Thus, the lower scores across all five critical aesthetic domains in radiated patients may carry some importance when evaluating the long-term goals of reconstruction patients.

Additional analysis of postoperative complications in radiated and nonradiated patients showed that the radiated cohort had a higher rate of overall complications. While radiation has an independent detrimental effect on tissue and thus increases the likelihood for
TABLE 5

The relationship between radiation and aesthetic domain scores*

\begin{tabular}{lcccc}
\hline $\begin{array}{l}\text { Dependent } \\
\text { variable }\end{array}$ & $\mathbf{B}(\mathbf{9 5 \%} \mathbf{C l})$ & $\boldsymbol{\beta}$ & $\mathbf{R}^{\mathbf{2}}$ & $\mathbf{P}$ \\
\hline Volume & $-0.07(-0.246$ to 0.106$)$ & -0.059 & 0.039 & 0.426 \\
Contour & $-0.108(-0.292$ to 0.076$)$ & -0.086 & 0.044 & 0.245 \\
Placement & $-0.228(-0.396$ to -0.060$)$ & -0.199 & 0.079 & $0.007^{\dagger}$ \\
Inframammary fold & $-0.081(-0.221$ to 0.059$)$ & -0.087 & 0.032 & 0.248 \\
Scarring & $-0.064(-0.266$ to 0.138$)$ & -0.048 & 0.022 & 0.527 \\
\hline
\end{tabular}

*Each linear regression model also included chemotherapy and smoking as separate predictors; ${ }^{\dagger}$ Statistically significant (ie, $P<0.05$ )

complications, it is presumed that having a greater number of active smokers and patients undergoing chemotherapy also contributed to complications in the radiated population. Our overall complication rate of $26.1 \%$ in radiated patients was lower than previously reported rates (ranging from $52.5 \%$ to $68 \%[9,42,43]$ ). The variance in rates is most likely attributable to the fact that previous authors included a broader range of adverse events in their rate calculation, including infections requiring oral antibiotics and hematomas. It may also reflect more refined patient selection by the surgeon, with certain radiated patients receiving autologous reconstruction rather than expanderimplant surgery. Using more stringent criteria to define a postoperative complication, we showed persistence of high complication rates, which attest to the predilection that radiated patients have for adverse events and substantiate the conclusion from other studies that radiation may lead to more complications $(2,3,42,43)$.

Our study was not without limitations. Patients with a difficult postoperative course potentially requiring conversion to autologous tissue-based reconstruction were not excluded from the study. However, in our single-surgeon cohort, exclusion of these patients would have limited the power of the study. While others value computer-assisted volumetric evaluations of photographs as the ideal method for aesthetic assessments, scoring scales present many advantages, including intuitively meaningful data, ease of use and lower costs. Therefore, we used a validated scale specific to breast cosmesis evaluation with welldescribed subcriteria. The specific scale used in the present study has significantly higher intra- and inter-rater reliability compared with scales without specific criteria such as visual analogue scales. Furthermore, we calculated kappa scores to statistically evaluate the inter-rater reliability of the four raters in our study, and all measures fell into the good or very good category (ie, $\kappa>0.60$ ). It is also important to address the clinical significance of our findings. It is our contention that these results are clinically relevant, particularly to long-term patient satisfaction; however, we hope to correlate these aesthetic scores with patient satisfaction scores in future work to further establish clinical significance.

\section{CONCLUSION}

The present study quantitatively assessed the impact of radiation on reconstructive and aesthetic outcomes following expander-implant breast reconstruction. Radiation adversely impacts breast contour and placement, with possible negative contributions to volume, inframammary fold definition and scarring, and results in higher rates of complications. By differentiating specific features of aesthetic outcomes impacted by radiation, these findings will enhance the management of patient expectations.

FUNDING: Lauren M Mioton is the recipient of a research fellowship that is funded by the Vanderbilt Medical Scholars Program through NIH CTSA grant UL1 RR 024975. 


\section{REFERENCES}

1. Iwahira Y, Nagase T, Nakagami G, Huang L, Ohta Y, Sanada H. Histopathological comparisons of irradiated and non-irradiated breast skin from the same individuals. J Plast Reconstr Aesthet Surg. 2012;65:1496-505.

2. Tibbs MK. Wound healing following radiation therapy: A review. Radiother Oncol 1997;42:99-106.

3. Drake DB, Oishi SN. Wound healing considerations in chemotherapy and radiation therapy. Clin Plast Surg 1995;22:31-7.

4. Haubner F, Ohmann E, Pohl F, Strutz J, Gassner HG. Wound healing after radiation therapy: Review of the literature. Radiat Oncol 2012;24:162.

5. Kronowitz SJ, Robb GL. Breast reconstruction with postmastectomy radiation therapy: Current issues. Plast Reconstr Surg 2004;114:950-60.

6. Rudolph R. Complications of surgery for radiotherapy skin damage. Plast Reconstr Surg 1982;70:179-85.

7. Rudolph R, Arganese T, Woodward M. The ultrastructure and etiology of chronic radiotherapy damage in human skin. Ann Plast Surg 1982;9:282-92.

8. Rudolph R, Utley J, Woodward M, Hurn I. The ultrastructure of chronic radiation damage in rat skin. Surg Gynecol Obstet 1981;152:171-8.

9. Berry T, Brooks S, Sydow N, et al. Complication rates of radiation on tissue expander and autologous tissue breast reconstruction. Ann Surg Oncol 2010;17(Suppl 3):202-10.

10. Hvilsom GB, Hölmich LR, Steding-Jessen M, et al. Delayed breast implant reconstruction: Is radiation therapy associated with capsular contracture or reoperations? Ann Plast Surg 2012;68:246-52.

11. Kronowitz SJ. Current status of implant-based breast reconstruction in patients receiving postmastectomy radiation therapy. Plast Reconstr Surg 2012;130:513e-524e.

12. Jhaveri JD, Rush SC, Kostroff K, et al. Clinical outcomes of postmastectomy radiation therapy after immediate breast reconstruction. Int J Radiat Oncol Biol Phys 2008;72:859-65.

13. Parsa AA, Jackowe DJ, Johnson EW, et al. Selection criteria for expander/implant breast reconstruction following radiation therapy. Hawaii Med J 2009;68:66-8.

14. Roostaeian J, Pavone L, Da Lio A, Lipa J, Festekjian J, Crisera C. Immediate placement of implants in breast reconstruction: patient selection and outcomes. Plast Reconstr Surg 2011;127:1407-16.

15. Cordeiro PG, Pusic AL, Disa JJ, McCormick B, VanZee K. Irradiation after immediate tissue expander/implant breast reconstruction: Outcomes, complications, aesthetic results, and satisfaction among 156 patients. Plast Reconstr Surg 2004;113:877-81.

16. Javaid M, Song F, Leinster S, Dickson MG, James NK. Radiation effects on the cosmetic outcomes of immediate and delayed autologous breast reconstruction: An argument about timing. Plast Reconstr Aesthet Surg 2006;59:16-26.

17. Lowery JC, Wilkins EG, Kuzon WM, Davis JA. Evaluations of aesthetic results in breast reconstruction: An analysis of reliability. Ann Plast Surg 1996;36:601-6.

18. Mahmood U, Hanlon AL, Koshy M, et al. Increasing national mastectomy rates for the treatment of early stage breast cancer. Ann Surg Oncol 2012 Nov 8. (Epub ahead of print).

19. Rosenberg SM, Tamimi RM, Gelber S, et al. Body image in recently diagnosed young women with early breast cancer. Psychooncology 2012 Nov 7. Epub ahead of print.

20. Chun YS, Verma K, Sinha I, et al. Impact of prior ipsilateral chest wall radiation on pedicled TRAM flap breast reconstruction. Ann Plast Surg 2012 Nov 1. Epub ahead of print.

21. McCarthy CM, Klassen AF, Cano SJ, et al. Patient satisfaction with postmastectomy breast reconstruction: A comparison of saline and silicone implants. Cancer 2010;116:5584-91.

22. Gross E, Hannoun-Levi JM, Rouanet P, et al. Evaluation of immediate breast reconstruction and radiotherapy: Factors associated with complications. Cancer Radiother 2010;14:704-10.

23. Lee BT, A Adesiyun T, Colakoglu S, et al. Postmastectomy radiation therapy and breast reconstruction: An analysis of complications and patient satisfaction. Ann Plast Surg 2010;64:679-83.

24. McKeown DJ, Hogg FJ, Brown IM, Walker MJ, Scott JR, Weiler-Mithoff EM. The timing of autologous latissimus dorsi breast reconstruction and effect of radiotherapy on outcome. J Plast Reconstr Aesthet Surg 2009;62:488-93.

25. Barry M, Kell MR. Radiotherapy and breast reconstruction: A meta-analysis. Breast Cancer Res Treat 2011;127:15-22.
26. Kronowitz SJ, Lam C, Terefe W, et al. A multidisciplinary protocol for planned skin-preserving delayed breast reconstruction for patients with locally advanced breast cancer requiring postmastectomy radiation therapy: 3-year follow-up. Plast Reconstr Surg 2011;127:2154-66.

27. Koutcher L, Ballangrud A, Cordeiro PG, et al. Postmastectomy intensity modulated radiation therapy following immediate expander-implant reconstruction. Radiother Oncol 2010;94:319-23.

28. Classen J, Nitzsche S, Wallwiener D, et al. Fibrotic changes after postmastectomy radiotherapy and reconstructive surgery in breast cancer: A retrospective analysis in 109 patients. Strahlenther Onkol 2010;186:630-6.

29. Wong JS, Ho AY, Kaelin CM, et al. Incidence of major corrective surgery after post-mastectomy breast reconstruction and radiation therapy. Breast J 2008;14:49-54.

30. Panettiere P, Marchetti L, Accorsi D. The serial free fat transfer in irradiated prosthetic breast reconstructions. Aesthetic Plast Surg 2009;33:695-700.

31. Serra-Renom JM, Muñoz-Olmo JL, Serra-Mestre JM. Fat grafting in postmastectomy breast reconstruction with expanders and prostheses in patients who have received radiotherapy: Formation of new subcutaneous tissue. Plast Reconstr Surg 2010;125:12-8.

32. Peled AW, Foster RD, Esserman LJ, Park CC, Hwang ES, Fowble B. Increasing the time to expander-implant exchange after postmastectomy radiation therapy reduces expander-implant failure. Plast Reconstr Surg 2012;130:503-9.

33. Robertson S, Wengström Y, Eriksen C, Sandelin K. Breast surgeons performing immediate breast reconstruction with implants assessment of resource-use and patient-reported outcome measures. Breast 2012;21:590-6.

34. McCarthy CM, Mehrara BJ, Riedel E, et al. Predicting complications following expander/implant breast reconstruction: An outcomes analysis based on preoperative clinical risk. Plast Reconstr Surg 2008;121:1886-92.

35. Stone HB, Coleman CN, Anscher MS, McBride WH. Effects of radiation on normal tissue: Consequences and mechanisms. Lancet Oncol 2003;4:529-36.

36. Lindegren A, Halle M, Docherty Skogh AC, Edsander-Nord A. Postmastectomy breast reconstruction in the irradiated breast: A comparative study of DIEP and latissimus dorsi flap outcome. Plast Reconstr Surg 2012;130:10-8.

37. Chang EI, Ly DP, Wey PD. Comparison of aesthetic breast reconstruction after skin-sparing or conventional mastectomy in patients receiving preoperative radiation therapy. Ann Plast Surg 2007;59:78-81.

38. McCarthy CM, Pusic AL, Disa JJ, McCormick BL, Montgomery LL, Cordeiro PG. Unilateral postoperative chest wall radiotherapy in bilateral tissue expander/implant reconstruction patients: A prospective outcomes analysis. Plast Reconstr Surg 2005;116:1642-7.

39. Rogers NE, Allen RJ. Radiation effects on breast reconstruction with the deep inferior epigastric perforator flap. Plast Reconstr Surg 2002;109:1919-24.

40. Kroll SS, Schusterman MA, Reece GP, Miller MJ, Smith B. Breast reconstruction with myocutaneous flaps in previously irradiated patients. Plast Reconstr Surg 1994;93:460-9.

41. Stone HB, Coleman CN, Anscher MS, McBride WH. Effects of radiation on normal tissue: consequences and mechanisms. Lancet Oncol 2003;4:529-36.

42. Spear SL, Onyewu C. Staged breast reconstruction with saline-filled implants in the irradiated breast: Recent trends and therapeutic implications. Plast Reconstr Surg 2000;105:930-42.

43. Krueger EA, Wilkins EG, Strawderman M, et al. Complications and patient satisfaction following expander/implant breast reconstruction with and without radiotherapy. Int J Radiat Oncol Biol Phys 2001;49:713.

44. Nava MB, Pennati AE, Lozza L, Spano A, Zambetti M, Catanuto G. Outcome of different timings of radiotherapy in implant-based breast reconstructions. Plast Reconstr Surg 2011;128:353-9.

45. Overgaard M, Hansen PS, Overgaard J, et al. Postoperative radiotherapy in high-risk premenopausal women with breast cancer who receive adjuvant chemotherapy. N Engl J Med 1997;337:949.

46. Ragaz K, Jackson S M, Le N, et al. Adjuvant radiotherapy and chemotherapy in node-positive premenopausal women with breast cancer. N Engl J Med 1997;337:956. 